\title{
Gene expression-based comparison of the human secretory neuroepithelia of the brain choroid plexus and the ocular ciliary body: potential implications for glaucoma
}

Sarah F Janssen ${ }^{1}$, Theo GMF Gorgels ${ }^{1}$, Jacoline B ten Brink ${ }^{1}$, Nomdo M Jansonius ${ }^{2}$ and Arthur AB Bergen ${ }^{1,3^{*}}$

\begin{abstract}
Background: The neuroepithelia of the choroid plexus (CP) in the brain and the ciliary body (CB) of the eye have common embryological origins and share similar micro-structure and functions. The CP epithelium (CPE) and the non-pigmented epithelium (NPE) of the CB produce the cerebrospinal fluid (CSF) and the aqueous humor (AH) respectively. Production and outflow of the CSF determine the intracranial pressure (ICP); production and outflow of the AH determine the intraocular pressure (IOP). Together, the IOP and ICP determine the translaminar pressure on the optic disc which may be involved in the pathophysiology of primary open angle glaucoma (POAG). The aim of this study was to compare the molecular machinery of the secretory neuroepithelia of the CP and CB (CPE versus NPE) and to determine their potential role in POAG.
\end{abstract}

Methods: We compared the transcriptomes and functional annotations of healthy human CPE and NPE. Microarray and bioinformatic studies were performed using an Agilent platform and the Ingenuity Knowledge Database (IPA).

Results: Based on gene expression profiles, we found many similar functions for the CPE and NPE including molecular transport, neurological disease processes, and immunological functions. With commonly-used selection criteria (fold-change $>2.5$, $p$-value $<0.05$ ), $14 \%$ of the genes were expressed significantly differently between CPE and NPE. When we used stricter selection criteria (fold-change $>5, p$-value $<0.001$ ), still $4.5 \%$ of the genes were expressed differently, which yielded specific functions for the CPE (ciliary movement and angiogenesis/ hematopoiesis) and for the NPE (neurodevelopmental properties). Apart from a few exceptions (e.g. SLC12A2, SLC4A4, SLC4A10, KCNA5, and SCN4B), all ion transport protein coding genes involved in CSF and AH production had similar expression profiles in CPE and NPE. Three POAG disease genes were expressed significantly higher in the CPE than the NPE, namely CDH1, CDKN2B and SIX1.

Conclusions: The transcriptomes of the CPE and NPE were less similar than we previously anticipated. High expression of CSF/AH production genes and candidate POAG disease genes in the CPE and NPE suggest that both might be involved in POAG.

\footnotetext{
* Correspondence: a.bergen@nin.knaw.nl

${ }^{1}$ Department of Clinical and Molecular Ophthalmogenetics, the Netherlands Institute for Neuroscience (NIN), Royal Netherlands Academy of Arts and Sciences (KNAW), Meibergdreef 47, Amsterdam 1105 BA, The Netherlands ${ }^{3}$ Department of Clinical Genetics, AMC, Amsterdam, The Netherlands Full list of author information is available at the end of the article
} 


\section{Background}

Neuroepithelial cells, which themselves are derived from embryonic stem cells, can be viewed as neural progenitor cells $[1,2]$. They appear during embryonic development and form the neuroectoderm of the neural tube [3]. They give rise to multiple cell types, such as neurons, astrocytes and oligodendrocytes. In addition, in specialized areas of the central nervous system (CNS), these cells retain their epithelial nature and differentiate into fluid-secreting cells: the neuroepithelia of the ocular ciliary body and the choroid plexus epithelium of the brain [4-9]. These tight single-cell layers function together with the outer blood-retina barrier and the blood-brain barrier to maintain CNS homeostasis and are implicated in diseases like age-related macular degeneration, primary open-angle glaucoma (POAG) and Alzheimer's disease.

In the literature, transcriptome analysis and functional predictions of human neuroepithelia, including the human retinal pigment epithelium [10] and ciliary body [11] in the eye and the choroid plexus epithelium (CPE) of the brain [12] have been described, but most studies are difficult to compare since they used different sampling methods, methodologies and bioinformatic techniques. Previously we determined the RNA expression profiles and predicted functional properties of five adult human neuroepithelia using a single microarray and bioinformatics platform: the central and peripheral retinal pigment epithelium [13-15], the pigmented and nonpigmented neural epithelia of the ocular ciliary body (CB) [16], and the choroid plexus neural epithelium (CPE) of the brain [17].

In the current study, we set out to compare the gene expression profiles and functional annotations of two, apparently closely related neural epithelia: the CPE, which produces the cerebrospinal fluid (CSF) of the brain and the $\mathrm{CB}$ epithelium $(\mathrm{CBE})$, which produces aqueous humor $(\mathrm{AH})$ of the eye.

The CPE and CBE resemble each other in many ways, as reviewed by Straziella and Ghersi-Egea [18] for the CPE and by Coca-Prados and Escribano [19] for the CBE. In summary, both epithelia are lobed neuroectodermal cell layers sealed by tight junctions, thereby creating diffusion barriers for most hydrophilic molecules between the blood and CNS. Both CPE and CBE produce colorless fluids, the CSF and $\mathrm{AH}$, respectively. The $\mathrm{CPE}$ and $\mathrm{CBE}$ regulate production, composition and reabsorption of these fluids and are involved in intracranial and intra-ocular pressure dynamics, respectively $[20,21]$. Both the CPE and CBE form villi that overly a loose extracellular matrix and fenestrated choroidal capillaries.

There are also major differences between the CPE and $\mathrm{CBE}$. Obviously, they are located in different parts of the
CNS: the CPE is located in the lateral, third and fourth ventricles of the brain, whereas the CBE resides in the posterior chamber of the eye. A major difference is that the CBE consists of two adjacent neuroectodermal layers: the non-pigmented (NPE) and the pigmented epithelium (PE), whereas the CPE consists of a single epithelial layer. Using large scale gene expression analysis and functional annotation, we recently showed that the NPE and PE layers are highly comparable: only $1 \%$ of the transcriptome was different between the NPE and PE [16].

The CPE and CBE are involved in the pressure dynamics in the brain and eye, respectively. The pressures of the ocular and cranial fluids uniquely meet at one location: the optic disc, situated at the point where the optic nerve leaves the eye. The optic disc contains the lamina cribrosa that supports the retinal nerve fibers where they leave the eye. The difference between the posteriorly directed IOP and anteriorly directed ICP on the optic disk is the translaminar pressure gradient. This translaminar pressure ultimately determines the forces applied to the lamina cribrosa and these forces appear to play a key role in a common age-related eye disease POAG. POAG is a progressive optic neuropathy with abnormal cupping of the optic nerve head (excavation) and loss of retinal ganglion cells. The pathogenesis of POAG is largely unknown, but an increased IOP is a major risk factor. Recent findings suggest that it is actually the translaminar pressure, rather than the IOP, that forms the risk factor for POAG and its subtype normal tension glaucoma (NTG) [22-29].

Since the CPE and CBE have a similar origin, structure and function, and together are involved in translaminar pressure dynamics, we were interested in the gene expression-based functional comparison of the human CPE and CBE. Previously, we found that the gene expression of the two ciliary epithelia, PE and NPE, resembled each other closely [16]. For the present study we chose to compare the CPE with the NPE (and not the $\mathrm{PE})$, since the NPE is non-pigmented and contains tight junctions, just like the CPE. The aims of this study were (1) to compare the gene expression profiles and functional annotation of the CPE and NPE in order to determine common properties and potential specific functions and (2) to determine CPE/NPE highly and specifically expressed genes coding for ion transport proteins involved in CSF/AH production and (3) for genes previously associated with POAG.

\section{Methods}

\section{Ethics statement}

This study was performed after institutional approval of the Netherlands Institute for Neuroscience, Amsterdam, Netherlands. The human CPE material was obtained from 
the Netherlands Brain Bank (Amsterdam, Netherlands). The human donor eyes were provided by the Corneabank Beverwijk, Netherlands. In accordance with the international declaration of Helsinki, the NBB and the Corneabank obtained permission from the donors for, respectively, brain and eye autopsy and the use of clinical information for research purposes. All human data were analyzed anonymously.

\section{Gene expression data of the human choroid plexus and ciliary body epithelia}

We used the gene expression data from our previouslypublished microarray studies of healthy human CPE (seven samples) (GSE49974; [17]) and NPE (seven samples) (GSE37957; [16]). The age of the donors varied between 39 and 73 years. Donors had neither history of any brain or eye disease nor any malignancies. The seven human CPE donors were all male, five human CBE donors were male and two female. Since several external or genetic factors may have influence on our human gene expression data, we could detect only consistent and significant similarities or differences between the selected samples. All RNA samples from each tissue were analyzed separately by microarray. The microarrays were performed against the same common reference sample, being human retinal pigment epithelium (RPE)/choroid. In this way, the CPE and NPE gene-expression data could be compared with each other. Human choroid plexus tissue was removed from the lateral ventricles of fresh post mortem brains. Whereas the gross anatomy of the CPE became somewhat distorted, the neuroepithelium could be identified easily on cryosections for laser dissection. Donor eyes were snap-frozen in their entirety, which maintained the overall structure of the ciliary body. Detailed description of cell sampling, RNA processing, microarray hybridization, and confirmation methodology of the microarray data were described elsewhere previously [16].

\section{Data analysis}

The microarray image files were analyzed and processed by Agilent Feature Extraction Software (Agilent Technologies, version 9.5.3.1) and mean intensities $(\log 2)$ were given to the spots. These mean intensities were normalized between arrays of the CPE and NPE in R (version 2.14.0 for Windows, R Development Core Team, 2009; NormalizeBetweenArrays with the 'aquantile' method). Next, the genes were ranked by expression level and assigned percentile ranks [13]. The expression datasets were functionally annotated using the Ingenuity Knowledge Base (Ingenuity ${ }^{\circ}$ Systems, version 11631407, www.ingenuity.com; assessed at August $27,2013)$. The ingenuity core-analysis yields information about biological functions, functional molecular networks, and canonical pathways. Functional molecular networks represent the interactions of molecules leading to biological functions that are attributed to a certain dataset of genes. Canonical pathways are the simplest representation of an (established) molecular pathway. The Ingenuity database contains millions of molecular and functional data points from experimental studies, available from both literature and online experimental databases such as PUBMED, the GWAS Database, GEO, and OMIM.

For the first functional analysis, genes were selected with the highest expression values (expression above 90th percentile [P90]) in both the CPE and NPE. This means that these genes have an expression intensity that falls into the highest $10 \%$ intensity values of the CPE and NPE microarrays $[13,16]$. These genes are referred to as the "Highly expressed CPE and NPE genes". Next, the gene expression data of the CPE and NPE was compared with a t-test in $\mathrm{R}$ and Benjamini-Hochberg correction for multiple testing (version 2.14.0 for Windows, $\mathrm{R}$ Development Core Team, 2009). Our initial selection criteria for differentially expressed genes were a foldchange $(\mathrm{FC})>2.5$ and a $p$-value $<0.05$. To identify larger and more specific differences, a relatively strict criteria of $\mathrm{FC}>5$ and a $p$-value $<0.001$ was used, and this resulted in a set of genes referred to as the "Significantly differentially expressed CPE and NPE genes". These significantly differentially expressed CPE and NPE genes were functionally annotated in the Ingenuity Knowledge Base (Ingenuity ${ }^{\circ}$ Systems, version 11631407, www.ingenuity.com; assessed at August 5, 2013). In addition, we looked for highly and significantly differentially expressed ion transport protein coding genes involved in $\mathrm{CSF} / \mathrm{AH}$ production in the CPE and NPE. The ionchannels and ion transporters that are involved in CSF and $\mathrm{AH}$ production were, respectively, reviewed by Brown et al. [30] and Civan et al. [20]. Ingenuity was searched for corresponding genes that code for these channels and transporters. In this way, we created a list of genes involved in CSF/AH production. Next, this list was compared with the "Highly expressed CPE and NPE genes" and "Significantly differentially expressed CPE and NPE genes" to find common or different features in $\mathrm{CPE}$ and NPE regarding CSF/AH production. Finally, we searched for (candidate) POAG disease genes that were highly or significantly differentially expressed in the CPE and NPE. To this end we compared the "Highly expressed CPE and NPE genes" and "Significantly differentially expressed CPE and NPE genes" with a list of 65 (candidate) POAG disease genes that we recently reviewed [31]

\section{Results}

\section{Comparison of the CPE and NPE transcriptome}

There were several functions that are apparently biologically important in both epithelial layers. These were (1) 
neurological function and disease (migration of neuroglia, Alzheimer's disease, Parkinson's disease, tauopathy, Leigh syndrome), (2) immunological and infectious diseases (allergy and autoimmune disease, viral infection pathways), (3) molecular transport, (4) hematological disease (myelodysplastic syndrome, lymphosarcoma, anemia), and (5) basic cellular (dys) functions. However, it is possible that similar expression of house-keeping genes in both tissues underlie some of these shared functional annotations.

The statistical comparison between the entire gene expression datasets of 30,589 unique genes of the CPE and NPE showed that many genes were also significantly differentially expressed between the CPE and NPE. Surprisingly, with the frequently used standard ANOVA selection criteria $(\mathrm{FC}>2.5$ and $p$-value $<0.05$; $[15,16])$, far more significantly differentially expressed genes (14\%) were found than we had expected a-priori. To identify the most important and specific differences, we subsequently chose a more strict selection criteria (FC $>5$ and $p$-value $<0.001)$. With these criteria, there were $760(2.5 \%)$ genes significantly more highly expressed in the CPE than in the NPE. Vice versa, there were 624 (2.0\%) genes significantly more highly expressed in the NPE out of a total of 30,589 unique genes. Tables 1 and 2 present the top-30 of "Significantly differentially expressed CPE and NPE genes" according to the strict criteria. The complete lists of the expressed genes in CPE and NPE can be found in Additional files 1 and 2, respectively.

\section{Functional annotation of the genes expressed significantly higher in CPE than in NPE}

Ingenuity attributed four major statistically significant biological functions to the CPE: (1) ciliary and flagella motion and primary ciliary dyskinesia, (2) development of blood vessels and angiogenesis and related diseases (vascular disease, occlusion of artery, arteriosclerosis), (3) molecular transport, and (4) several types of cancer (adenocarcinoma, epithelial neoplasia, cancer of lung, uterine endometrium, and ovary). Using the same dataset, Ingenuity subsequently built 25 functional molecular CPE networks. Figure 1 shows as an example, a diagram of network 1 that represents the gene and protein interactions leading to ciliary movement and dyskinesia. This network is functionally annotated with "Developmental and hereditary disorders and respiratory disease". The other 24 functional molecular network diagrams can be found in Additional file 3. After correction for multiple testing, there were no statistically significant canonical pathways specifically assigned by Ingenuity to the CPE compared with the NPE.

\section{Functional annotation of the genes expressed significantly higher in NPE than in CPE}

Ingenuity assigned four major statistically significant biological functions to the NPE compared to the CPE. The
Table 1 Top-30 genes significantly higher expressed in CPE compared to NPE

\begin{tabular}{|c|c|c|c|}
\hline Gene name & Systematic name & FC & $p$-value \\
\hline$T T R$ & NM_000371 & 4307.5 & $2.38 \mathrm{E}-12$ \\
\hline$S L C 24 A 4$ & NM_153646 & 425.1 & $3.49 \mathrm{E}-14$ \\
\hline W60781 & W60781 & 390.8 & 4.65E-09 \\
\hline ARMC3 & NM_173081 & 196.7 & $7.12 \mathrm{E}-13$ \\
\hline$K L$ & NM_153683 & 191.7 & 4.53E-10 \\
\hline SPAG6 & NM_012443 & 171.5 & $2.74 \mathrm{E}-11$ \\
\hline SLCO1C1 & NM_017435 & 134.0 & $1.96 \mathrm{E}-11$ \\
\hline KLK11 & NM_144947 & 127.7 & 1.47E-14 \\
\hline IL13RA2 & NM_000640 & 97.5 & $4.59 \mathrm{E}-12$ \\
\hline FAM81B & NM_152548 & 90.5 & $2.08 \mathrm{E}-11$ \\
\hline$E F C A B 1$ & NM_024593 & 88.1 & $4.38 \mathrm{E}-13$ \\
\hline THC2741529 & THC2741529 & 82.8 & 1.86E-09 \\
\hline DNER & NM_139072 & 82.6 & $2.08 \mathrm{E}-12$ \\
\hline KIAA1456 & NM_020844 & 77.6 & 2.09E-12 \\
\hline C13orf26 & NM_152325 & 77.5 & 1.13E-12 \\
\hline SLC4A10 & NM_022058 & 73.1 & $9.42 \mathrm{E}-10$ \\
\hline FLJ23049 & NM_024687 & 71.8 & $3.49 \mathrm{E}-12$ \\
\hline KCNA5 & NM_002234 & 70.4 & 1.97E-11 \\
\hline NAT8L & NM_178557 & 69.9 & $5.20 \mathrm{E}-10$ \\
\hline SPAG8 & NM_172312 & 62.9 & 1.47E-10 \\
\hline$B \cup B 1 B$ & NM_001211 & 59.2 & 7.40E-08 \\
\hline AIM2 & NM_004833 & 55.6 & $9.11 \mathrm{E}-13$ \\
\hline THC2657259 & THC2657259 & 55.0 & $6.28 \mathrm{E}-11$ \\
\hline GRM8 & NM_000845 & 54.9 & $5.38 \mathrm{E}-10$ \\
\hline HRK & NM_003806 & 54.6 & 8.93E-11 \\
\hline POLE & AF128542 & 54.3 & 4.24E-09 \\
\hline FABP4 & NM_001442 & 52.4 & $8.89 \mathrm{E}-10$ \\
\hline C2orf39 & NM_145038 & 50.6 & 2.09E-12 \\
\hline CLIC6 & NM_053277 & 49.7 & 2.07E-11 \\
\hline KIAA1199 & NM_018689 & 47.9 & 1.10E-12 \\
\hline
\end{tabular}

first and most significant biological function was (1) nervous system development, and more specifically neuronal development of sensory organ, head, body axis, eye, forebrain, brain, and telencephalon. This functionality also comprised neurological and ophthalmic diseases (seizure, epilepsy, schizophrenia, bipolar disorder, and congenital anomalies of the eye). Examples of genes underlying this NPE functionality are $A L D H 1 A 1$, ATOH7, CYP1B1, MSX2, OTX1, PAX6, PVRL3, RP1, SEMA5A, SIX6, and SOX4 (eye development) and BMP2, FGFR1, GAP43, GLI3, GSX2, HES1, PAX6, RELN, SLIT1, SOX3, SOX4, and ZIC3 (brain development). For the total list, see Additional file 4. Another statistically significant function was formation of cellular protrusions and plasma membrane projections. This function was 
Table 2 Top-30 genes expressed significantly higher in NPE compared to CPE

\begin{tabular}{|c|c|c|c|}
\hline Gene name & Systematic name & FC & $\mathrm{p}$-value \\
\hline$A O C 3$ & NM_003734 & 375.2 & $4.24 \mathrm{E}-10$ \\
\hline FGFBP2 & NM_031950 & 272.4 & $9.92 \mathrm{E}-11$ \\
\hline THC2677285 & THC2677285 & 268.8 & $9.11 \mathrm{E}-13$ \\
\hline LOC92196 & NM_001017920 & 250.9 & $3.32 \mathrm{E}-11$ \\
\hline CPAMD8 & NM_015692 & 214.9 & $9.80 \mathrm{E}-11$ \\
\hline HSD17B2 & NM_002153 & 195.9 & 9.23E-12 \\
\hline CD96 & NM_198196 & 162.3 & $9.23 \mathrm{E}-12$ \\
\hline AK124698 & AK124698 & 161.5 & 7.00E-10 \\
\hline GRM1 & NM_000838 & 128.9 & $2.64 \mathrm{E}-13$ \\
\hline PCSK2 & NM_002594 & 125.6 & $2.49 \mathrm{E}-11$ \\
\hline CLRN1 & NM_174878 & 118.3 & 1.09E-12 \\
\hline LIPC & NM_000236 & 107.8 & $2.40 \mathrm{E}-12$ \\
\hline ATPIA2 & NM_000702 & 105.1 & 2.77E-08 \\
\hline C8orf47 & NM_173549 & 89.4 & $2.38 \mathrm{E}-12$ \\
\hline TFPI2 & NM_006528 & 88.7 & 2.44E-09 \\
\hline DSC1 & NM_004948 & 87.4 & 1.20E-10 \\
\hline GPR64 & NM_001079858 & 86.5 & $8.89 \mathrm{E}-12$ \\
\hline SLC5A8 & NM_145913 & 85.6 & 5.97E-14 \\
\hline LHX2 & NM_004789 & 77.8 & $2.64 \mathrm{E}-13$ \\
\hline RAX & NM_013435 & 77.7 & 1.70E-11 \\
\hline$A B \mid 3 B P$ & NM_015429 & 76.6 & 1.65E-09 \\
\hline FAM83D & NM_030919 & 75.9 & 4.79E-12 \\
\hline BHLHB5 & NM_152414 & 75.4 & 5.31E-10 \\
\hline SLITRK5 & NM_015567 & 66.0 & 5.56E-10 \\
\hline THC2636507 & THC2636507 & 64.2 & 1.45E-08 \\
\hline THC2676797 & THC2676797 & 62.6 & 7.23E-12 \\
\hline DSCR8 & NM_203429 & 61.8 & $2.38 \mathrm{E}-12$ \\
\hline OXGR1 & NM_080818 & 60.7 & 4.41E-11 \\
\hline LRRN1 & NM_020873 & 56.7 & $9.48 \mathrm{E}-12$ \\
\hline KIAA1727 & NM_033393 & 55.6 & 3.40E-09 \\
\hline
\end{tabular}

based on 47 genes expressed significantly higher in NPE, for example genes involved in actin function (ANK3, ARGHGAP24, ENC1, MARCKS, PALLD), genes involved in filopodium formation and cytoskeleton organization (MCF2, RHOU) and axonal growth and guidance (CNTN4, GAP43, LRRC4C, SEMA3A, TIAM1, TIAM2). For the total list, see Additional file 5. Finally, we identified the functions of molecular transport, and several types of cancer (adenocarcinoma, epithelial neoplasia, cancer of lung).

Subsequently, from the same dataset, Ingenuity built 25 functional molecular networks significantly present in the NPE, but not in the CPE. Figure 2 presents, as an example, a diagram of network 1 that shows specific neurodevelopmental functions of the NPE, annotated with top functions "Embryonic, organ and organismal development". The other 24 functional molecular network diagrams can be found in Additional file 6. After correction for multiple testing, Ingenuity did not assign statistically significant canonical pathways specific for the NPE compared to the CPE.

\section{CPE and NPE expressed genes involved in CSF and $\mathrm{AH}$ production}

We constructed a list of 157 coding genes corresponding to all the CPE and CBE ion channels and ion transporters proteins as described by Brown et al. [30] and Civan et al. [20] (see Additional file 7). Table 3 presents a list of ion channels and ion-transporters of which at least some of the coding genes were highly and/or significantly differentially expressed in the CPE and NPE, in order to find common or different features in CPE and NPE regarding CSF/AH production. Based on our gene expression data, all these ion channels and ion transporters were present in both epithelia. Eight coding genes were both highly expressed in CPE and NPE (SLC12A7, ATP1A1, ATP1A2, ATP1B1, ATP1B2, $A T P 1 B 3, K C N J 13$, and $A Q P 1), 13$ were expressed significantly higher in the CPE compared to the NPE (ATP1B1, SLC12A2, SLC4A2, SLC4A10, KCNA5, KCNE1, KCNF1, $K C N H 2, K C N K 1, K C N N 2, K C N N 3, \quad S C N 2 A$, and $A Q P 4)$, and 10 higher in the NPE compared to the CPE (ATP1A1, ATP1B3, SLC4A4, KCNA4, KCNB2, KCNG1, $K C N S 1, S C N 2 B, S C N 3 B$, and $S C N 4 B)$.

\section{CPE and NPE expressed genes previously associated with POAG}

We compared a recently constructed list of 65 candidate POAG genes (reviewed in [31]) with the genes that were highly and/or significantly differently expressed in the CPE and NPE. Table 4 presents the results. We found 10 candidate POAG genes that were highly expressed in both the CPE and NPE (AKAP13, C1QBP, CHSY1, COL8A2, CYP1B1, FBN1, IBTK, MFN2, TMCO1, and TMEM248), three genes that were expressed significantly higher in the CPE (CDH1, CDKN2B, and SIX1), and six genes that were expressed significantly higher in the NPE (ATOH7, CYP1B1, FBN1, MYOC, PAX6, and SIX6).

\section{Discussion}

The gene expression data of the brain CPE and the NPE of the CBE from the eye were compared. The CPE and NPE are both secretory neuroepithelia, which share a common embryological origin and important structural and functional features (fluid production, brain and eye homeostasis and pressure dynamics) but also exhibit substantial anatomical differences (location, single (CPE) or double (CBE) layered). Together, the $\mathrm{CPE}$ and $\mathrm{CBE}$ are ultimately involved in building the translaminar 


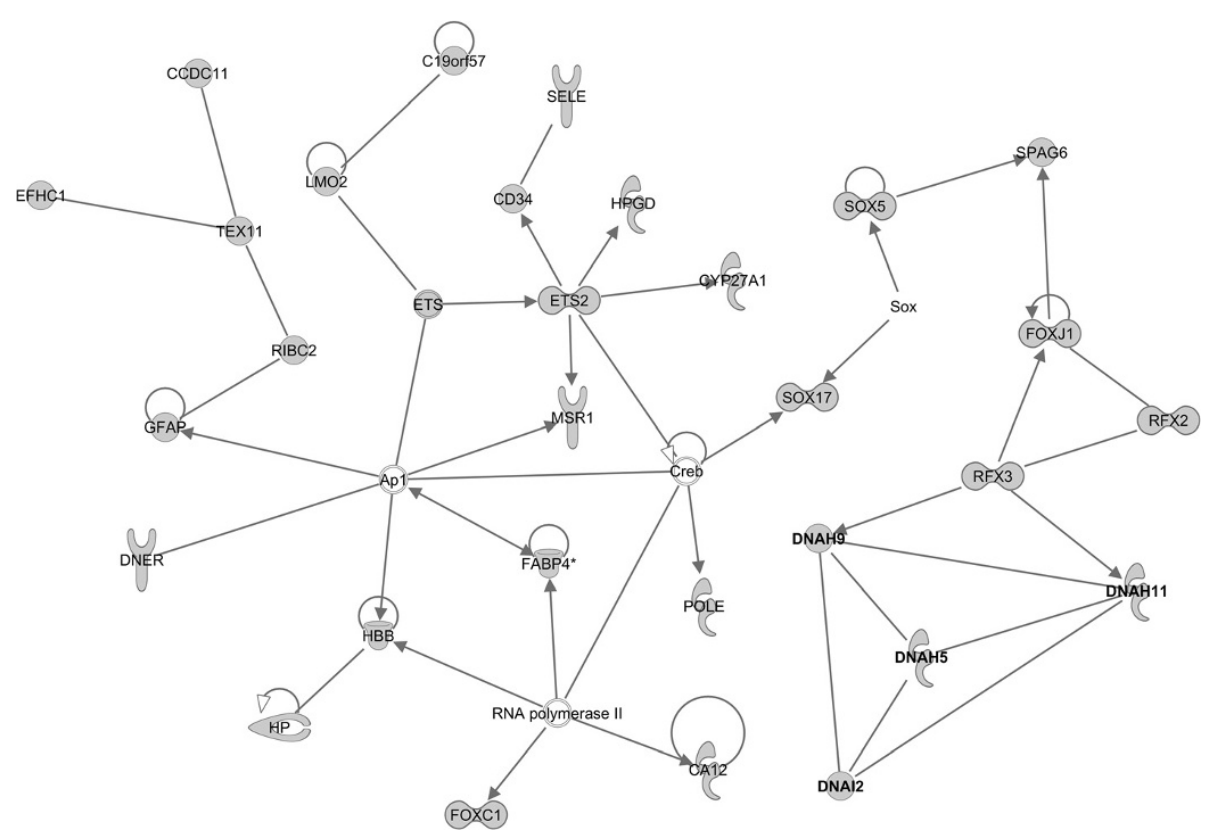

Figure 1 Molecular network of genes expressed significantly more highly in the brain choroid plexus epithelium compared to the non-pigmented epithelium of the eye. Example of a molecular network generated by Ingenuity software. Grey symbols represent genes expressed more highly in the CPE than in the NPE. Transparent entries are molecules inserted by the knowledge database. Gene names are abbreviated according to those used in GenBank. Solid lines between molecules indicate direct physical or functional relationships between molecules (such as regulating and interacting protein domains). The genes DNAH5, DNAH9, DNAH11 and DNAI2 indicated in bold, code for dynein proteins. Dyneins keep the microtubules of the cilia together and promote the movement of the cilia. Mutations in these genes can cause primary ciliary dyskinesia. The main functionalities given by Ingenuity for this entire molecular network are "Developmental and hereditary disorder and respiratory disease". Reproduced with permission.

pressure of CSF and $\mathrm{AH}$ on the optic disc. A disturbed translaminar pressure is a risk factor for POAG and NTG.

\section{Comparison of the CPE and NPE transcriptome}

It had been anticipated that the transcriptomes and predicted functionalities of the CPE and NPE in the current study would be highly similar. After all, using (initially) the same criteria, methodology and platform, the neuroepithelial transcriptomes of the ocular NPE and PE differed only by $1 \%$ [16] and the transcriptomes of the macular and peripheral RPE only by $1-5 \%$ [15]. Several overlapping functionalities for the CPE and NPE most highly expressed genes were found, including neurological function and diseases, immunological properties, and molecular transport. However, unexpectedly, there were also large differences between the two neuroepithelia. In the initial analysis, in which we applied the same selection criteria $(\mathrm{FC}>2.5$ and $p$-value $<0.05)$ as used in our previous neuroepithelial microarray studies $[13,15,16]$, there was a large, $14 \%$ difference (data not shown); in our final analysis $(\mathrm{FC}>5$ and $p$-value $<0.001$ ) this was still $4.5 \%$. Hence, although the transcriptomes of the two neuroepithelia showed substantial overlap, there were large differences as well.
Previously published data showed many molecular similarities between CPE and CBE, but also some differences: for example the ion channels and ion transporters involved in CSF and AH production. These were widely studied and extensively reviewed by Brown et al. [30] for the CPE and by Civan et al. [20] for the CBE. These reviews reported that most of the ion channels and ion-transporters involved in the CSF/AH production are found in both the $\mathrm{CPE}$ and $\mathrm{CBE}$, for example $\mathrm{Na}^{+} / \mathrm{K}^{+}$-ATPase, $\mathrm{Na}^{+} / \mathrm{K}^{+} / 2 \mathrm{Cl}^{-}$-symporters, $\mathrm{Cl}^{-} / \mathrm{HCO}^{-}$ and $\mathrm{Na}^{+} / \mathrm{H}^{+}$exchangers, and aquaporins. However, there were also some ion transport proteins in the CPE that have not been identified in the $\mathrm{CBE}$, for example $\mathrm{Na}^{+} / \mathrm{HCO}^{-}$and $\mathrm{K}^{+} / \mathrm{Cl}^{-}$symporters. On the other hand, $\mathrm{Na}^{+} / \mathrm{Cl}^{-}$exchangers were found in the CBE, but not (yet) in the CPE $[20,30]$.

\section{Predicted CPE functionalities not present in the NPE Function of cilia}

The most important predicted function found in the CPE, but not in the NPE, was genes for ciliary motion and primary ciliary dyskinesia. Cilia, which consist of bundles of microtubules held together by dyneins, are essential for CSF flow in the brain ventricles. Hydrocephalus is a common sign of primary ciliary dyskinesia, 


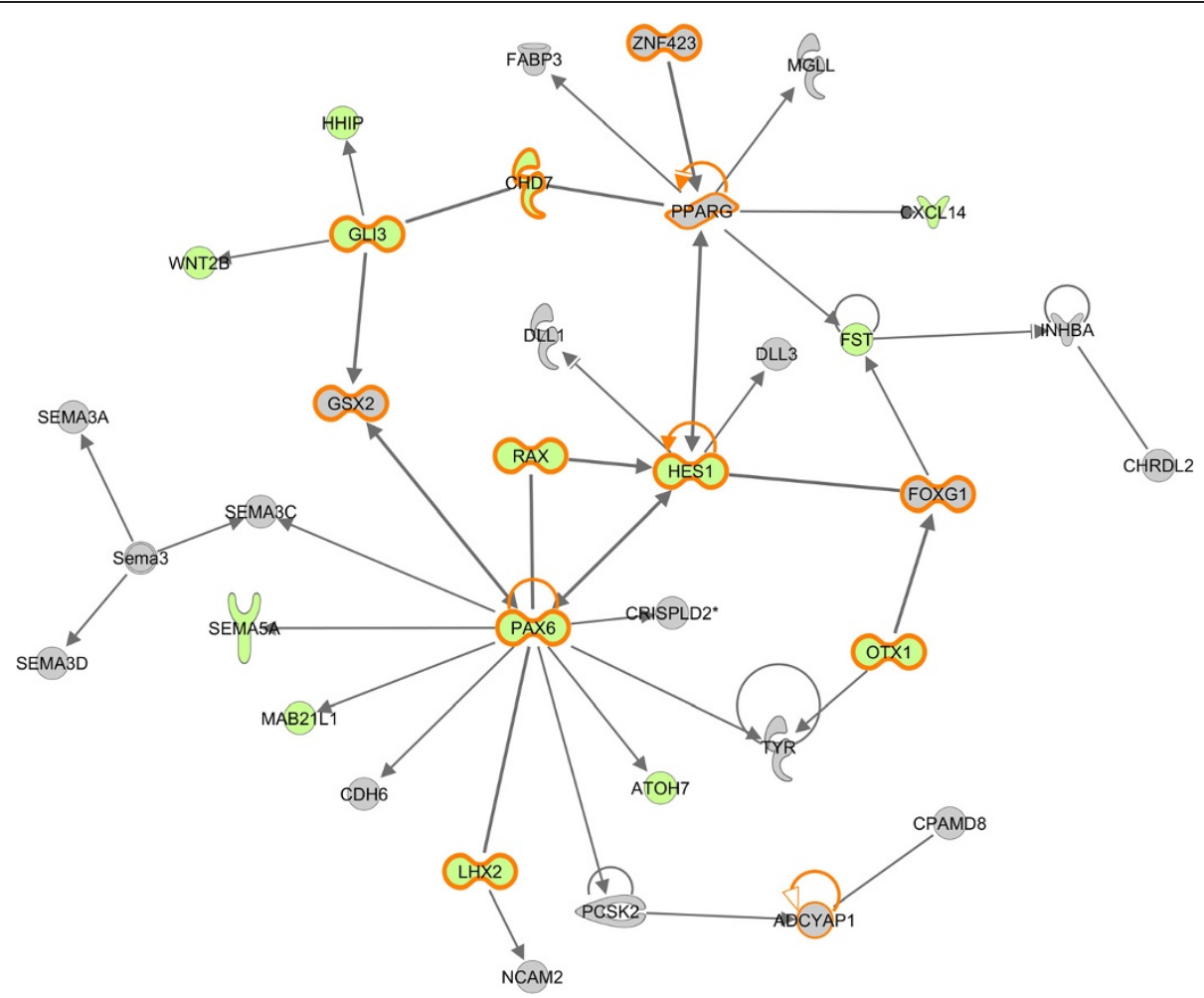

Figure 2 Molecular network of genes expressed significantly more highly in non-pigmented epithelium of the eye compared to the brain choroid plexus epithelium. Example of a molecular network generated by Ingenuity software. Gene names are abbreviated according to those used in GenBank. Solid lines between molecules indicate direct physical or functional relationships between molecules (such as regulating and interacting protein domains). This network contains many genes involved in brain and nervous system development (orange bordered symbols) and eye development (green filled symbols). The main functionalities given by Ingenuity for this entire molecular network are "Embryonic organ and organismal development". Reproduced with permission.

a disease caused by mutations in dynein proteins [32,33]. A detailed inspection of the expression datasets showed that six dynein coding genes (DNAH5, DNAH7, DNAH9, $D N A H 11, D N A I 1$, and DNAI2) were expressed significantly more highly in the CPE compared to the NPE. Vice versa, there were no dynein coding genes expressed more highly in the NPE compared to the CPE. Hence, our data are in line with the idea that ciliary function is biologically more important in CPE than in NPE.

\section{Angiogenesis}

Another important CPE function that was not present in the NPE was "angiogenesis and development of blood vessels". Ingenuity yielded this function because of 57 relevant genes expressed significantly higher in the CPE than in the NPE, most importantly ACE2, ADRA2B, AHR, FN1, FOXC1, GATA6, HGF, HHEX, KLF2, PGF, PTHLH, SERPINF1, and TEK (for the complete list, see Additional file 8). The appearance of this function could be explained either by a technical artifact or by a genuine biological reason. The CPE samples are much more closely entangled with blood vessels than the NPE. Thus, potential contamination of CPE tissue with blood vessel cells during laser dissection microscopy may underlie this finding. We previously showed that cellular contamination of adjacent tissue is a possible limitation of (our) cellular microarray approach [13]. Alternatively, the CPE could actually have a specific function that is not present in the NPE. This function could be extramedullary hematopoiesis $(\mathrm{EH})$, which previously has been assigned to the human and mouse CPE [31]. Indeed, the functional molecular network 4 ("Hematological system development and function and hematopoiesis") built by Ingenuity of significantly higher expressed CPE genes, also points to this specific property (Additional file 3). $\mathrm{EH}$ is a compensatory mechanism of hematopoiesis in sites other than the bone marrow, and some case reports point to a role of EH in the CPE [34-36]. We could not find published reports of possible presence of $\mathrm{EH}$ in the NPE.

\section{Predicted NPE functions not present in the CPE Neuronal development}

The first and most significant predicted function for the NPE not present in the CPE was "development of neuronal tissues and organs, including eye, retina, brain and forebrain". The potential neural embryological properties of the 
Table 3 Genes coding for ion channels and transporters involved in CSF and AH production in the CPE and NPE

\begin{tabular}{|c|c|c|c|c|c|c|}
\hline \multirow{2}{*}{$\begin{array}{l}\text { Ion channels and transporters } \\
\mathrm{Na}^{+} / \mathrm{K}^{+} \text {ATPase }\end{array}$} & \multirow{2}{*}{$\frac{\text { Present in }}{C P E \text { and } C B E}$} & \multirow{2}{*}{$\begin{array}{l}\text { Coding genes } \\
\text { ATP1A1 }\end{array}$} & \multicolumn{2}{|c|}{ High gene expr. } & \multicolumn{2}{|c|}{ Sign. diff. gene expr. } \\
\hline & & & \multicolumn{2}{|c|}{ Both } & & $\overline{N P E}$ \\
\hline & & ATP1A2 & \multicolumn{2}{|c|}{ Both } & & \\
\hline & & ATP1A3 & \multicolumn{2}{|l|}{ CPE } & & \\
\hline & & ATP1A4 & & & & \\
\hline & & ATP1B1 & \multicolumn{2}{|c|}{ Both } & CPE & \\
\hline & & ATP1B2 & \multicolumn{2}{|c|}{ Both } & & \\
\hline & & ATP1B3 & \multicolumn{2}{|c|}{ Both } & & NPE \\
\hline \multirow[t]{2}{*}{$\mathrm{Na}^{+} / 2 \mathrm{Cl}^{-} / \mathrm{K}^{+}$co-transport } & CPE and CBE & $S L C 12 A 1$ & \multirow{2}{*}{\multicolumn{2}{|c|}{ CPE }} & & \\
\hline & & $S L C 12 A 2$ & & & CPE & \\
\hline $\mathrm{Na}^{+} / \mathrm{Cl}^{-}$symport & CBE & $S L C 12 A 3$ & & & & \\
\hline \multirow[t]{5}{*}{$\mathrm{K}^{+} / \mathrm{Cl}^{-}$symport } & CPE & SLC12A4 & & & & \\
\hline & & SLC12A5 & & & & \\
\hline & & SLC12A6 & & & & \\
\hline & & SLC12A7 & & & & \\
\hline & & SLC12A9 & & & & \\
\hline \multirow[t]{3}{*}{$\mathrm{Cl}^{-} / \mathrm{HCO}^{-}$exchanger } & CPE and CBE & SLCAA1 & & & & \\
\hline & & $S L C 4 A 2$ & & & CPE & \\
\hline & & $S L C 4 A 3$ & & & & \\
\hline \multirow[t]{6}{*}{$\mathrm{Na}^{+} / \mathrm{HCO}^{-}$symport } & CPE & SLC4A4 & & NPE & & NPE \\
\hline & & SLC4A5 & & & & \\
\hline & & SLC4A7 & & & & \\
\hline & & $S L C 4 A 8$ & & & & \\
\hline & & SLC4A9 & & & & \\
\hline & & SLC4A10 & CPE & & CPE & \\
\hline \multirow[t]{6}{*}{$\mathrm{Na}^{+} / \mathrm{H}^{+}$exchanger } & CPE and $\mathrm{CBE}$ & SLC9A1 & & & & \\
\hline & & SLC9A2 & & & & \\
\hline & & SLC9A3 & & & & \\
\hline & & SLC9A4 & & & & \\
\hline & & SLC9A5 & & & & \\
\hline & & SLC9A6 & & & & \\
\hline \multirow[t]{13}{*}{$\mathrm{K}^{+}$channel } & CPE and $C B E$ & KCNA4 & & & & NPE \\
\hline & & KCNA5 & CPE & & CPE & \\
\hline & & KCNAB1 & & NPE & & \\
\hline & & KCNB2 & & & & NPE \\
\hline & & KCNE1 & & & CPE & \\
\hline & & KCNF1 & & & CPE & \\
\hline & & KCNG1 & & & & NPE \\
\hline & & $\mathrm{KCNH} 2$ & & & CPE & \\
\hline & & KCNJ13 & & & & \\
\hline & & KCNK1 & CPE & & CPE & \\
\hline & & KCNN2 & & & CPE & \\
\hline & & KCNN3 & & & CPE & \\
\hline & & KCNS1 & & & & NPE \\
\hline
\end{tabular}


Table 3 Genes coding for ion channels and transporters involved in CSF and AH production in the CPE and NPE (Continued)

\begin{tabular}{|c|c|c|c|c|c|}
\hline \multirow[t]{7}{*}{$\mathrm{Cl}^{-}$channel } & CPE and CBE & CLCN1 & & & \\
\hline & & CLCN2 & & & \\
\hline & & CLCN3 & & & \\
\hline & & CLCN4 & & & \\
\hline & & CLCN5 & & & \\
\hline & & CLCN6 & & & \\
\hline & & CLCN7 & & & \\
\hline \multirow[t]{14}{*}{$\mathrm{Na}^{+}$channel } & CPE and CBE & SCNIA & & & \\
\hline & & SCNIB & & & \\
\hline & & SCN2A & & CPE & \\
\hline & & $S C N 2 B$ & & & NPE \\
\hline & & SCN3A & & & \\
\hline & & $S C N 3 B$ & & & NPE \\
\hline & & SCN4A & & & \\
\hline & & $S C N 4 B$ & NPE & & NPE \\
\hline & & SCN5A & & & \\
\hline & & SCN7A & & & \\
\hline & & SCN8A & & & \\
\hline & & SCN9A & & & \\
\hline & & SCN1OA & & & \\
\hline & & SCN11A & & & \\
\hline \multirow[t]{10}{*}{ Water channel } & $\mathrm{CPE}$ and $\mathrm{CBE}$ & $A Q P 1$ & Both & & \\
\hline & & $A Q P 2$ & & & \\
\hline & & $A Q P 3$ & & & \\
\hline & & $A Q P 4$ & & CPE & \\
\hline & & AQP5 & & & \\
\hline & & $A Q P 7$ & & & \\
\hline & & AQP8 & & & \\
\hline & & $A Q P 9$ & & & \\
\hline & & $A Q P 10$ & & & \\
\hline & & $A Q P 11$ & & & \\
\hline
\end{tabular}

This table lists the ion channels and ion transporters involved in cerebrospinal fluid (CSF)/aqueous humor (AH) production, their presence in choroid plexus epithelium (CPE) and/or non-pigmented epithelium (NPE) of the ciliary body epithelium according to literature [20,30] and the gene expression profiles in the CPE and NPE according to our microarray gene expression studies. Column 1: Ion channels and transporters involved in CSF/AH production. For the $\mathrm{K}^{+}$channel, we only presented the highly and/or statistical significant different expressed genes of the CPE and NPE; Column 2 - Present in: The presence of the different ion channels and ion transporters are reviewed in [30] for the CPE and [20] for the NPE; Column 3 - Coding genes: the genes coding for the ion channels and ion transporters listed in column 1; Column 4 - High gene expr.: Here we indicate the genes that are highly expressed in the CPE and/or NPE according to our gene expression microarray data of the CPE and NPE. Highly expressed gene are genes with mean expression values $>90$ th percentile. This means that these genes have an expression intensity that falls into the highest $10 \%$ intensity values of the microarray. Both = high expression in both CPE and NPE; Column 5 - Sign. diff. gene expr.: Here we indicate the genes that were statistically significant higher expressed in the CPE or NPE compared with the NPE and CPE, respectively, according to our gene expression microarray data of the CPE and NPE. The selection criteria were fold change $>5$ and $p$-value $<0.001$.

CBE have been a topic of fierce recent discussion. The pars plana and the ciliary marginal zone of the CBE may, or may not, contain retinal progenitor cells, and there may even be differences between animal species. Some authors reported the presence of specific retinal stem cell or progenitor cell markers, such as NES, MITF, PAX6, SIX3, Rx, FGF2, and CHX10 [37-42]. Isolated CBE neural progenitor cells were shown to proliferate and differentiate in vitro into neural spheres and possible photoreceptor-like cells [37,43-50], although this was not found in all studies $[51,52]$. Interestingly, our gene expression data are primarily of the pars plicata of the human NPE, not from the ora serrata, but, even here, some embryological properties seem to be present in the adult neuroepithelium. 


\begin{tabular}{|c|c|c|}
\hline Candidate POAG disease genes & High gene expr. & Sign. diff. gene expr. \\
\hline$A P O E$ & CPE & \\
\hline AKAP13 & Both & \\
\hline ATOH7 & & NPE \\
\hline$C I Q B P$ & Both & \\
\hline $\mathrm{CDH} 1$ & CPE & CPE \\
\hline CDKN2B & & CPE \\
\hline $\mathrm{CHSY}_{1}$ & Both & \\
\hline COL8A2 & Both & \\
\hline CYP1B1 & Both & NPE \\
\hline FBN1 & Both & NPE \\
\hline GSTM1 & CPE & \\
\hline IBTK & Both & \\
\hline MFN2 & Both & \\
\hline MYOC & NPE & NPE \\
\hline OPTN & CPE & \\
\hline PAX6 & NPE & NPE \\
\hline RFTN1 & NPE & \\
\hline$S I X 1$ & & CPE \\
\hline SIX6 & NPE & NPE \\
\hline TMCO1 & Both & \\
\hline TMEM248 & Both & \\
\hline
\end{tabular}

High gene expr: Genes that are highly expressed in the CPE and/or NPE according to our gene expression microarray data of the CPE and NPE. Highly expressed gene are genes with mean expression values >90th percentile. Both = high expression in both CPE and NPE. Sign. diff. gene expr.: Genes that are statistically significant higher expressed in the CPE or NPE compared with the NPE and CPE, respectively, according to our gene expression microarray data. The selection criteria were fold change $>5$ and $p$-value $<0.001$.

\section{Cellular protrusions}

The second predicted function of the NPE was "formation of cellular protrusions and plasma membrane projections". The reason why this function is apparently more prominent in the NPE is currently not clear. After all, both the NPE and CPE contain actin and both cell types have filopodia. Possibly, the attachment of lens zonule fibers to the NPE may play a role in this finding. Future research is warranted.

\section{Ion channels and ion transporters involved in CSF and $\mathrm{AH}$} production

The genes coding for the ion channels and ion-transporters involved in CSF and AH production had highly similar expression patterns in both tissues. Indeed, in the literature, some of these proteins were already identified in the CPE and CBE, such as ATP1A1, ATP1B1 and ATP1B2 [20,30], AQP1 [53,54] and SLC12A7 [55]. However, there are some significant expression differences in specific genes, which point to (subtle) differences in CSF and AH production: namely 13 specifically-expressed genes in the CPE and 10 in the NPE. To compare, a study of the molecular background of $\mathrm{AH}$ production in the $\mathrm{CBE}$, the NPE and PE only showed four specifically expressed genes in the PE and none in the NPE [56]. At the protein level, previous studies showed expression of SLC12A2 [57], SLC4A2 [58], and SLC4A10 [59] in the CPE and expression of SLC4A4 [60] and sodium channels [61] in CBE. However, these finding were not proof that these proteins definitely differ between $\mathrm{CPE}$ and $\mathrm{CBE}$, and comparative studies on protein level in both CPE and CPE are necessary to determine this. The differences between CPE and NPE could be a starting point for further biochemical, physiological and pharmacological research. Perhaps, these differences will open the door for specific drug delivery to the brain and the eye after systemic treatment as for example in a systemic drug that simultaneously increases ICP and lowers the IOP for POAG/NTG treatment.

\section{Potential CPE and NPE involvement in POAG}

Both the CPE and CBE may, ultimately, play a role in the development of POAG (see Background section), and especially in the development of NTG [31]. Ten (AKAP13, C1QBP, CHSY1, COL8A2, CYP1B1, FBN1, IBTK, MFN2, TMCO1 and TMEM248) of the 65 candidate POAG disease genes were highly expressed in both CPE and NPE, 
which might indicate overlapping pathobiological mechanisms of POAG in the two epithelia. On the other hand, we also identified three candidate POAG disease genes, $C D H 1$, $C D K N 2 B$ and SIX1, which were expressed more highly in the CPE than in the NPE. CDKN2B regulates cell cycle and growth, SIX1 is involved in developmental processes and CDH1 is a cell-cell adhesion glycoprotein. Interestingly, mutations in $C D K N 2 B$ were previously implicated in NTG [62-65]. In addition, mutations in both $C D K N 2 B$ and SIX1 were previously associated with the vertical-cup-disc-ratio, an endophenotype of POAG [66,67], and not, for example, with IOP. Vice versa, we found six (candidate) POAGdisease genes significantly higher expressed in the NPE than in the CPE (ATOH7, CYP1B1, FBN1, MYOC, PAX6, and SIX6). The potential involvement of these genes in POAG via the CPE and CBE is currently not clear.

As mentioned in the Background section, it seems that not only an increase in IOP but also a decrease in ICP could be a risk factor for POAG [22-29,68-70]. Thus, manipulation of either IOP or ICP, together or apart, would be a possible form of POAG treatment. For example, alphaadrenergic receptors are present in the both NPE and CPE albeit with differences in affinity and effect upon stimulation [71-73]. Our expression data show that $A D R A 2 B$ (an alpha-2-adrenergic receptor) is expressed more highly in the CPE compared to NPE and ADRA1B (an alpha1 -adrenergic receptor) is expressed more highly in the NPE compared to the CPE. Of specific interest are the alpha-2 adrenoceptors in the brain and eye. Chiou et al. [71] found that intraocular administration of an alpha- 2 antagonist (yohimbine) resulted in a decreased IOP in cats, whereas McCormick et al. [73] showed that an intravenous administered alpha- 2 antagonist (tolazine) resulted in an increased ICP. These findings might suggest that an intravenous alpha-2 antagonist is an ideal treatment option for POAG and NTG: it lowers the IOP and increases the ICP, thereby changing the translaminar pressure on both sides. Chiou et al. [71] also found that intraocular treatment with an alpha-2 agonist (clonidine) resulted in a decreased IOP (but less effective than alpha-2 antagonist). In the brain, intravenous alpha-2 agonist (xylazine) resulted also in a decreased ICP, making this agent less interesting for the dual, systemic treatment of POAG/NTG. However, more research is warranted, to prove these findings and hypothesis, to specify which alpha-2 antagonist does both decrease IOP and increase ICP, and if this approach is a good treatment option.

\section{Conclusions}

The gene expression patterns and predicted functions of the CPE and NPE overlap (molecular transport, immunological functions), but also show substantial differences. The ion channels and ion-transporters involved in CSF and AH production share the same expression profiles for most of their coding genes in CPE and NPE, with a few exceptions. The CPE showed specific functions in ciliary movement and angiogenesis/hematopoiesis compared to the NPE. Vice versa, the NPE analysis yielded specific neurodevelopmental properties not present in the CPE. In POAG and NTG, the CPE and NPE could act together in creating a disturbed, net posteriorly directed translaminar pressure over the optic disc, where brain and eye meet.

\section{Additional files}

\begin{abstract}
Additional file 1: Total list of genes expressed significantly higher in CPE compared to NPE. Selection criteria were a fold change $>5$ and $p$-value $<0.001$
\end{abstract}

Additional file 2: Total list of genes expressed significantly higher in NPE compared to CPE. Selection criteria were a fold change $>5$ and $p$-value $<0.001$

Additional file 3: Molecular networks 2-25 generated by the Ingenuity software from the genes expressed significantly higher in the CPE compared to NPE. Grey symbols represent genes expressed significantly higher in the CPE. Transparent entries are molecules inserted by the knowledge database. Gene names are abbreviated according to those used in GenBank. Solid lines indicate direct physical or functional relationships between molecules (such as regulating and interacting protein domains). The main functionalities given by Ingenuity for this entire molecular network are shown in the diagrams. Reproduced with permission

Additional file 4: Genes in the NPE expressed significantly higher than in CPE involved in the biological function of development.

Additional file 5: Genes in the NPE expressed significantly higher than in CPE involved in the biological function of cellular protrusions.

Additional file 6: Molecular networks generated by the Ingenuity software from the genes expressed significantly higher in the NPE compared to CPE. Grey symbols represent genes expressed significantly higher in the NPE. Transparent entries are molecules inserted by the knowledge database. Gene names are abbreviated according to those used in GenBank. Solid lines indicate direct physical or functional relationships between molecules (such as regulating and interacting protein domains). The main functionalities given by Ingenuity for this entire molecular network are shown in the diagrams. Reproduced with permission.

Additional file 7: Genes coding ion transport proteins involved in CSF and AH production. We constructed a list of 157 coding genes corresponding to all the CPE and CBE ion transport proteins as described by Brown et al. [30] and Civan et al. [20].

Additional file 8: Genes expressed significantly higher in the CPE than in NPE involved in the biological function of angiogenesis.

\section{Abbreviations}

$\mathrm{AH}$ : Aqueous humor; EH: Extramedullary hematopoiesis; CBE: Ciliary body epithelium; CNS: Central nervous system; CPE: Choroid plexus epithelium; CSF: Cerebrospinal fluid; ICP: Intracranial pressure; IOP: Intraocular pressure; NPE: Non-pigmented epithelium; NTG: Normal tension glaucoma; PE: Pigmented epithelium; POAG: Primary open angle glaucoma; RPE: Retinal pigment epithelium.

Competing interests

The authors declare that they have no competing interests.

\section{Authors' contributions}

SJ carried out the microarray studies and drafted the manuscript; TG participated in study design and helped to draft the manuscript; JB carried out the microarray studies; NJ participated in study design and helped to 
draft the manuscript; $A B$ participated in study design and drafted the manuscript. All authors read and approved the final manuscript.

\section{Author details}

${ }^{1}$ Department of Clinical and Molecular Ophthalmogenetics, the Netherlands Institute for Neuroscience (NIN), Royal Netherlands Academy of Arts and Sciences (KNAW), Meibergdreef 47, Amsterdam 1105 BA, The Netherlands. ${ }^{2}$ Department of Ophthalmology, University of Groningen, University Medical Center Groningen, Groningen, The Netherlands. ${ }^{3}$ Department of Clinical Genetics, AMC, Amsterdam, The Netherlands.

Received: 19 November 2013 Accepted: 26 January 2014

Published: 29 January 2014

\section{References}

1. Alvarez-Buylla A, Garcia-Verdugo JM, Tramontin AD: A unified hypothesis on the lineage of neural stem cells. Nat Rev Neurosci 2001, 2:287-293.

2. Leclerc C, Neant I, Moreau M: Early neural development in vertebrates is also a matter of calcium. Biochimie 2011, 93:2102-2111.

3. Preston M, Sherman LS: Neural stem cell niches: roles for the hyaluronanbased extracellular matrix. Front Biosci (Schol Ed) 2011, 3:1165-1179.

4. Johansson PA, Irmler M, Acampora D, Beckers J, Simeone A, Gotz M: The transcription factor Otx2 regulates choroid plexus development and function. Development 2013, 140:1055-1066.

5. Larsen KB, Lutterodt M, Rath MF, Moller M: Expression of the homeobox genes PAX6, OTX2, and OTX1 in the early human fetal retina. Int J Dev Neurosci 2009, 27:485-492.

6. Nicholson-Flynn K, Hitchcock-DeGregori SE, Levitt P: Restricted expression of the actin-regulatory protein, tropomyosin, defines distinct boundaries, evaginating neuroepithelium, and choroid plexus forerunners during early CNS development. J Neurosci 1996, 16:6853-6863.

7. Von FJ, Wizenmann A, Gotz M: The transcription factors Emx1 and Emx2 suppress choroid plexus development and promote neuroepithelial cel fate. Dev Biol 2006, 296:239-252.

8. Watanabe M, Kang YJ, Davies LM, Meghpara S, Lau K, Chung CY, Kathiriya J, Hadjantonakis AK, Monuki ES: BMP4 sufficiency to induce choroid plexus epithelial fate from embryonic stem cell-derived neuroepithelial progenitors. J Neurosci 2012, 32:15934-15945.

9. Zhao $S$, Chen $Q$, Hung FC, Overbeek PA: BMP signaling is required for development of the ciliary body. Development 2002, 129:4435-4442.

10. Whitmore SS, Braun TA, Skeie JM, Haas CM, Sohn EH, Stone EM, Scheetz TE, Mullins RF: Altered gene expression in dry age-related macular degeneration suggests early loss of choroidal endothelial cells. Mol Vis 2013, 19:2274-2297.

11. Wagner AH, Anand VN, Wang WH, Chatterton JE, Sun D, Shepard AR,

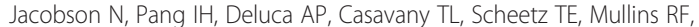
Braun TA, Clark AF: Exon-level expression profiling of ocular tissues. Exp Eye Res 2013, 111:105-111.

12. Hasselblatt M, Böhm C, Tatenhorst L, Dinh V, Newrzella D, Keyvani K, Jeibmann A, Buerger $\mathrm{H}$, Rickert $\mathrm{CH}$, Paulus W: Identification of nove diagnostic markers for choroid plexus tumors: a microarray-based approach. Am J Surg Pathol 2006, 30:66-74.

13. Booij JC, Van SS, Swagemakers SM, Essing AH, Verkerk AJ, Van Der Spek PJ, Gorgels TG, Bergen AA: Functional annotation of the human retinal pigment epithelium transcriptome. BMC Genomics 2009, 10:164.

14. Booij JC, Ten Brink JB, Swagemakers SM, Verkerk AJ, Essing AH, van der Spek PJ, Bergen AA: A new strategy to identify and annotate human RPE-specific gene expression. PLOS One 2010, 5:e9341.

15. van Soest SS, de Wit GM, Essing AH, Ten Brink JB, Kamphuis W, De Jong PT, Bergen AA: Comparison of human retinal pigment epithelium gene expression in macula and periphery highlights potential topographic differences in Bruch's membrane. Mol Vis 2007, 13:1608-1617.

16. Janssen SF, Gorgels TG, Bossers K, Ten Brink JB, Essing AH, Nagtegaal M, van der Spek PJ, Jansonius NM, Bergen AA: Gene expression and functional annotation of the human ciliary body epithelia. PLOS One 2012, 7:e44973

17. Janssen SF, van der Spek SJF, Ten Brink JB, Essing AHW, Gorgels TGMF, van der Spek PJ, Jansonius NM, Bergen AAB: Gene expression and functional annotation of the human and mouse choroid plexus epithelium. PlosOne 2013, 8(12):e83345

18. Strazielle N, Ghersi-Egea JF: Choroid plexus in the central nervous system: biology and physiopathology. J Neuropathol Exp Neurol 2000, 59:561-574.
19. Coca-Prados M, Escribano J: New perspectives in aqueous humor secretion and in glaucoma: the ciliary body as a multifunctional neuroendocrine gland. Prog Retin Eye Res 2007, 26:239-262.

20. Civan MM, Macknight AD: The ins and outs of aqueous humour secretion. Exp Eye Res 2004, 78:625-631

21. Johanson CE, Duncan JA 3rd, Klinge PM, Brinker T, Stopa EG, Silverberg GD: Multiplicity of cerebrospinal fluid functions: New challenges in health and disease. Cerebrospinal Fluid Res 2008, 5:10

22. Jonas JB, Berenshtein $E$, Holbach $L$ : Anatomic relationship between lamina cribrosa, intraocular space, and cerebrospinal fluid space. Invest Ophthalmol Vis Sci 2003, 44:5189-5195

23. Morgan WH, Yu DY, Balaratnasingam C: The role of cerebrospinal fluid pressure in glaucoma pathophysiology: the dark side of the optic disc. J Glaucoma 2008, 17:408-413.

24. Morgan WH, Yu DY, Cooper RL, Alder VA, Cringle SJ, Constable IJ: The influence of cerebrospinal fluid pressure on the lamina cribrosa tissue pressure gradient. Invest Ophthalmol Vis Sci 1995, 36:1163-1172.

25. Berdahl JP, Fautsch MP, Stinnett SS, Allingham RR: Intracranial pressure in primary open angle glaucoma, normal tension glaucoma, and ocular hypertension: a case-control study. Invest Ophthalmol Vis Sci 2008, 49:5412-5418

26. Berdahl JP, Allingham RR, Johnson DH: Cerebrospinal fluid pressure is decreased in primary open-angle glaucoma. Ophthalmology 2008, 115:763-768.

27. Ren R, Jonas JB, Tian G, Zhen Y, Ma K, Li S, Wang H, Li B, Zhang X, Wang N: Cerebrospinal fluid pressure in glaucoma: a prospective study. Ophthalmology 2010, 117:259-266.

28. Ren R, Wang N, Zhang X, Cui T, Jonas JB: Trans-lamina cribrosa pressure difference correlated with neuroretinal rim area in glaucoma. Graefes Arch Clin Exp Ophthalmol 2011, 249:1057-1063.

29. Wang $N$, Xie $X$, Yang D, Xian J, Li Y, Ren R, Peng X, Jonas JB, Weinreb RN: Orbital cerebrospinal fluid space in glaucoma: the Beijing intracranial and intraocular pressure (iCOP) study. Ophthalmology 2012, 119:2065-2073.

30. Brown PD, Davies SL, Speake T, Millar ID: Molecular mechanisms of cerebrospinal fluid production. Neuroscience 2004, 129:957-970.

31. Janssen SF, Gorgels TG, Ramdas WD, Klaver CC, van Duijn CM, Jansonius NM, Bergen AA: The vast complexity of primary open angle glaucoma: Disease genes, risks, molecular mechanisms and pathobiology. Prog Retin Eye Res 2013, 37:31-67.

32. Banizs B, Pike MM, Millican CL, Ferguson WB, Komlosi P, Sheetz J, Bell PD, Schwiebert EM, Yoder BK: Dysfunctional cilia lead to altered ependyma and choroid plexus function, and result in the formation of hydrocephalus. Development 2005, 132:5329-5339.

33. Narita K, Kawate T, Kakinuma N, Takeda S: Multiple primary cilia modulate the fluid transcytosis in choroid plexus epithelium. Traffic 2010, 11:287-301.

34. Dhechakaisaya S, Shuangshoti S, Susakares A: Extramedullary hematopoiesis of cranial dura mater and choroid plexus and terminal convulsions in a patient with thalassemia-hemoglobin E disease. J Med Assoc Thai 1979, 62:503-511.

35. Eskazan AE, Ar MC, Baslar Z: Intracranial extramedullary hematopoiesis in patients with thalassemia: a case report and review of the literature. Transfusion 2012, 52:1715-1720.

36. Tabesh H, Shekarchizadeh A, Mahzouni P, Mokhtari M, Abrishamkar S, Abbasi FS: An intracranial extramedullary hematopoiesis in a 34-year-old man with beta thalassemia: a case report. J Med Case Rep 2011, 5:580.

37. Ahmad I, Tang L, Pham H: Identification of neural progenitors in the adult mammalian eye. Biochem Biophys Res Commun 2000, 270:517-521.

38. Bhatia B, Singhal S, Lawrence JM, Khaw PT, Limb GA: Distribution of Muller stem cells within the neural retina: evidence for the existence of a ciliary margin-like zone in the adult human eye. Exp Eye Res 2009, 89:373-382.

39. Das AV, James J, Rahnenfuhrer J, Thoreson WB, Bhattacharya S, Zhao X Ahmad I: Retinal properties and potential of the adult mammalian ciliary epithelium stem cells. Vision Res 2005, 45:1653-1666.

40. Fischer AJ, Reh TA: Transdifferentiation of pigmented epithelial cells: a source of retinal stem cells? Dev Neurosci 2001, 23:268-276.

41. Lord-Grignon J, Abdouh M, Bernier G: Identification of genes expressed in retinal progenitor/stem cell colonies isolated from the ocular ciliary body of adult mice. Gene Expr Patterns 2006, 6:992-999. 
42. Martinez-Navarrete GC, Angulo A, Martin-Nieto J, Cuenca N: Gradual morphogenesis of retinal neurons in the peripheral retinal margin of adult monkeys and humans. J Comp Neurol 2008, 511:557-580.

43. Abburi C, Prabhakar S, Kalra J, Huria A, Anand A: Vascular endothelial growth factor (VEGF) induced proliferation of human fetal derived ciliary epithelium stem cells is mediated by jagged-N cadherin pathway. Curr Neurovasc Res 2013, 10:93-102.

44. Ballios BG, Clarke L, Coles BL, Shoichet MS, van der Kooy D: The adult retinal stem cell is a rare cell in the ciliary epithelium whose progeny can differentiate into photoreceptors. Biol Open 2012, 1:237-246.

45. Demontis GC, Aruta C, Comitato A, De MA, Marigo V: Functional and molecular characterization of rod-like cells from retinal stem cells derived from the adult ciliary epithelium. PLoS One 2012, 7:e33338.

46. Fang Y, Cho KS, Tchedre K, Lee SW, Guo C, Kinouchi H, Fried S, Sun X, Chen DF: Ephrin-A3 suppresses Wnt signaling to control retinal stem cell potency. Stem Cells 2013, 31:349-359.

47. Inoue T, Coles BL, Dorval K, Bremner R, Bessho Y, Kageyama R, Hino S, Matsuoka M, Craft CM, Mclnnes RR, et al: Maximizing functional photoreceptor differentiation from adult human retinal stem cells. Stem Cells 2010, 28:489-500.

48. MacNeil A, Pearson RA, MacLaren RE, Smith AJ, Sowden JC, Ali RR: Comparative analysis of progenitor cells isolated from the iris, pars plana, and ciliary body of the adult porcine eye. Stem Cells 2007, 25:2430-2438.

49. Tropepe V, Coles BL, Chiasson BJ, Horsford DJ, Elia AJ, Mclnnes RR, van der Kooy D: Retinal stem cells in the adult mammalian eye. Science 2000, 287:2032-2036.

50. Xu H, Sta Iglesia DD, Kielczewski JL, Valenta DF, Pease ME, Zack DJ, Quigley HA: Characteristics of progenitor cells derived from adult ciliary body in mouse, rat, and human eyes. Invest Ophthalmol Vis Sci 2007, 48:1674-1682.

51. Cicero SA, Johnson D, Reyntjens S, Frase S, Connell S, Chow LM, Baker SJ Sorrentino BP, Dyer MA: Cells previously identified as retinal stem cells are pigmented ciliary epithelial cells. Proc Natl Acad Sci USA 2009, 106:6685-6690.

52. Gualdoni S, Baron M, Lakowski J, Decembrini S, Smith AJ, Pearson RA, Ali RR, Sowden JC: Adult ciliary epithelial cells, previously identified as retinal stem cells with potential for retinal repair, fail to differentiate into new rod photoreceptors. Stem Cells 2010, 28:1048-1059.

53. Longatti $P$, Basaldella L, Orvieto E: Dei Tos A, Martinuzzi A: Aquaporin(s) expression in choroid plexus tumours. Pediatr Neurosurg 2006, 42:228-233.

54. Verkman AS, Ruiz-Ederra J, Levin MH: Functions of aquaporins in the eye. Prog Retin Eye Res 2008, 27:420-433.

55. Karadsheh MF, Byun N, Mount DB, Delpire E: Localization of the KCC4 potassium-chloride cotransporter in the nervous system. Neuroscience 2004, 123:381-391.

56. Janssen SF, Gorgels TGMF, van der Spek PJ, Jansonius NM, Bergen AAB: In silico analysis of the molecular machinery underlying aquoeus humor production: potential implication for glaucoma. J CLin Bioinform 2013, $3: 21$.

57. Plotkin MD, Kaplan MR, Peterson LN: Gullans SRm Hebert SC, Delpire E: Expression of the $\mathrm{Na}(+)-\mathrm{K}(+)-2 \mathrm{Cl}$ - cotransporter $\mathrm{BSC} 2$ in the nervous system. Am J Physiol 1997, 272:C173-SC183.

58. Wu Q, Delpire E, Hebert SC, Strange K: Functional demonstration of $\mathrm{Na}+$ $-\mathrm{K}+-2 \mathrm{Cl}$ - cotransporter activity in isolated, polarized choroid plexus cells. Am J Physiol 1998, 275:C1565-C1572.

59. Christensen HL, Nguyen AT, Pedersen FD, Damkier HH: Na + dependent acid-base transporters in the choroid plexus; insights from slc4 and slc9 gene deletion studies. Front Physion 2013, 4:304.

60. Bok D, Schibler MJ, Pushkin A, Sassani P, Abuladze N, Naser Z, Kurtz I: Immunolocalization of electrogenic sodium-bicarbonate cotransporters pNBC1 and kNBC1 in the rat eye. Am J Physiol Renal Physiol 2001, 281:F920-F935.

61. Watsky MA, Cooper K, Rae JL: Sodium channels in ocular epithelia. Pflugers Arch 1991, 419:454-459.

62. Burdon KP, Crawford A, Casson RJ, Hewitt AW, Landers J, Danoy P, Mackey DA, Mitchell P, Healey PR, Craig JE: Glaucoma risk alleles at CDKN2B-AS1 are associated with lower intraocular pressure, normal-tension glaucoma, and advanced glaucoma. Ophthalmology 2012, 119:1539-1545.

63. Mabuchi F, Sakurada Y, Kashiwagi K, Yamagata Z, lijima H, Tsukahara S: Association between genetic variants associated with vertical cup-to-disc ratio and phenotypic features of primary open-angle glaucoma. Ophthalmology 2012, 119:1819-1825.

64. Takamoto M, Kaburaki T, Mabuchi A, Araie M, Amano S, Aihara M, Tomidokoro A, Iwase A, Mabuchi F, Kashiwagi K, et al: Common variants on chromosome 9p21 are associated with normal tension glaucoma. Plos One 2012, 7:e40107.

65. Wiggs $J$, Yaspan BL, Hauser MA, Kang JH, Allingham RR, Olson LM, Abdrabou W, Fan BJ, Wang DY, Brodeur W, et al: Common variants at 9p21 and $8 \mathrm{q} 22$ are associated with increased susceptibility to optic nerve degeneration in glaucoma. PLoS Genet 2012, 8:e1002654.

66. Dimasi DP, Burdon KP, Hewitt AW, Fitzgerald J, Wang JJ, Healey PR, Mitchell P, Mackey DA, Craig JE: Genetic investigation into the endophenotypic status of central corneal thickness and optic disc parameters in relation to open-angle glaucoma. Am J Ophthalmol 2012, 154:833-842.

67. Ramdas WD, van Koolwijk LM, Ikram MK, Jansonius NM, De Jong PT, Bergen AA, Isaacs A, Amin N, Aulchenko YS, Wolfs RC, et al: A genome-wide association study of optic disc parameters. PLOS Genet 2010, 6:e1000978.

68. Jonas JB, Wang N: Intracranial pressure and glaucoma. J Glaucoma 2013, 22(Suppl 5):S13-S14.

69. Killer HE, Miller NR, Flammer J, Meyer P, Weinreb RN, Remonda L, Jaggi GP. Cerebrospinal fluid exchange in the optic nerve in normal-tension glaucoma. Br J Ophthalmol 2012, 96:544-548.

70. Wostyn P, De GV, Van DD, Audenaert K, De Deyn PP: Senescent changes in cerebrospinal fluid circulatory physiology and their role in the pathogenesis of normal-tension glaucoma. Am J Ophthalmol 2013, 156:5-14.

71. Chiou GC: Effects of alpha 1 and alpha 2 activation of adrenergic receptors on aqueous humor dynamics. Life Sci 1983, 32:1699-1704.

72. Haywood JR, Vogh BP: Some measurements of autonomic nervous system influence on production of cerebrospinal fluid in the cat. J Pharmacol Exp Ther 1979, 208:341-346.

73. McCormick JM, McCormick PW, Zabramski JM, Spetzler RF: Intracranial pressure reduction by a central alpha-2 adrenoreceptor agonist after subarachnoid hemorrhage. Neurosurgery 1993, 32:974-979.

doi:10.1186/2045-8118-11-2

Cite this article as: Janssen et al:: Gene expression-based comparison of the human secretory neuroepithelia of the brain choroid plexus and the ocular ciliary body: potential implications for glaucoma. Fluids and Barriers of the CNS 2014 11:2

\section{Submit your next manuscript to BioMed Central and take full advantage of:}

- Convenient online submission

- Thorough peer review

- No space constraints or color figure charges

- Immediate publication on acceptance

- Inclusion in PubMed, CAS, Scopus and Google Scholar

- Research which is freely available for redistribution

Submit your manuscript at www.biomedcentral.com/submit
C) BioMed Central 